\title{
"Tear Drops in the Duodenum": Uncommon Cause of Iron Deficiency Anemia in Adults
}

\author{
Isma N. Javed ${ }^{1}$, Rutaba Tajammal ${ }^{1}$, Sardar H. Ijaz ${ }^{1}$, Nazir Ahmad ${ }^{2}$, Sultan Mahmood ${ }^{3}$
}

1. Internal Medicine, University of Oklahoma Health Sciences Center, Oklahoma City, USA 2. Internal Medicine, Saint Anthony Hospital, Oklahoma City, USA 3. Gastroenterology, Marshfield Clinic, Marshfield, USA

Corresponding author: Isma N. Javed, isma-javed@ouhsc.edu

\begin{abstract}
A 64-year-old man presented to the internal medicine resident clinic with fatigue and abdominal pain of sixmonth duration. He did not have diarrhea, hematemesis, melena, or hematochezia. Physical examination was unremarkable. Laboratory findings were consistent with iron deficiency anemia. Upper and lower gastrointestinal (GI) endoscopies revealed normal findings. Duodenal biopsy showed trophozoites (teardrop-shaped) morphologically consistent with Giardia duodenalis. He was prescribed metronidazole and iron replacement therapy, with a resultant improvement in symptoms as well as lab values at the fourmonth follow-up visit.
\end{abstract}

Received 04/22/2019

Review began 04/30/2019 Review ended 08/26/2019 Published 08/30/2019

๑) Copyright 2019 Javed et al. This is an open access article distributed under the terms of the Creative Commons Attribution License CC-BY 3.0., which permits unrestricted use, distribution, and reproduction in any medium, provided the original author and source are credited.
Categories: Internal Medicine, Gastroenterology, Infectious Disease

Keywords: iron deficiency anemia, anemia, giardiasis, fatigue, geriatric patients, giardia lamblia, metronidazole, iron deficiency

\section{Introduction}

Giardia duodenalis (also known as Giardia lamblia) is a protozoan parasite that commonly affects young children, travelers [1], and immunocompromised individuals. Giardiasis is an important cause of foodborne/water-borne diseases [2]. The fecal-oral route is the most common mode of transmission [3]. It is more common in children than in adults [4]. Giardia has been reported as a leading parasite causing enteric infections in the United States [5]. We report a case of giardiasis in an adult man, without typical symptoms or travel history, manifesting as iron deficiency anemia.

\section{Case Presentation}

A 64-year-old man with a medical history significant for hypertension and tobacco abuse presented to the internal medicine clinic, complaining of fatigue and abdominal pain of six-month duration. He denied any hematemesis, melena, or hematochezia. The physical exam was unremarkable. Laboratory findings were significant for microcytic hypochromic anemia with hemoglobin level $8 \mathrm{~g} / \mathrm{dl}$, mean cell volume $70.6 \mathrm{fl}$, and mean cell hemoglobin $21.1 \mathrm{pg}$. Serum vitamin B12 and folate were normal. The iron profile panel showed a low iron level, low iron saturation, and low ferritin, with an increased total iron-binding capacity. The celiac panel was negative. He was referred for an esophagogastroduodenoscopy (EGD) and a colonoscopy. The colonoscopy revealed normal findings. EGD showed normal mucosa. The biopsies from the stomach were negative for Helicobacter pylori (H. pylori). Duodenal biopsy showed normal mucosa and trophozoite forms (tear-drop-shaped) morphologically consistent with Giardia duodenalis (Figures 1-2). CD117 and Giemsa stains also showed positivity for Giardia duodenalis (Figure 3). The patient was treated with a one-week course of $400 \mathrm{mg}$ metronidazole three times a day. He was also given a prescription for $325 \mathrm{mg}$ ferrous sulfate once daily. At the four-month follow-up, the patient reported a marked improvement in his symptoms. Repeat complete blood count showed hemoglobin of $14 \mathrm{~g} / \mathrm{dl}$. 


\section{Cureus}

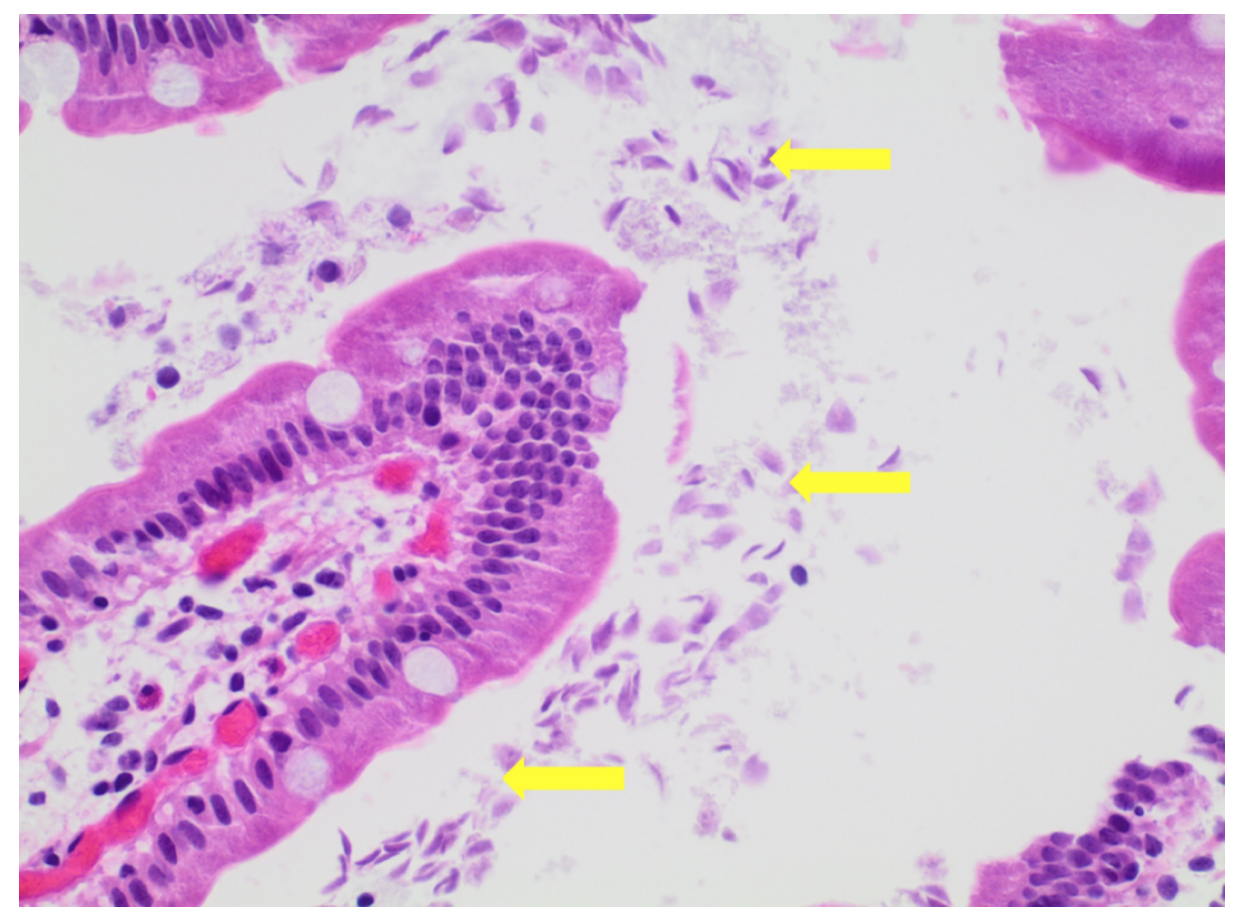

FIGURE 1: H \& E at 40x showing Giardia duodenalis surrounding the entire villus

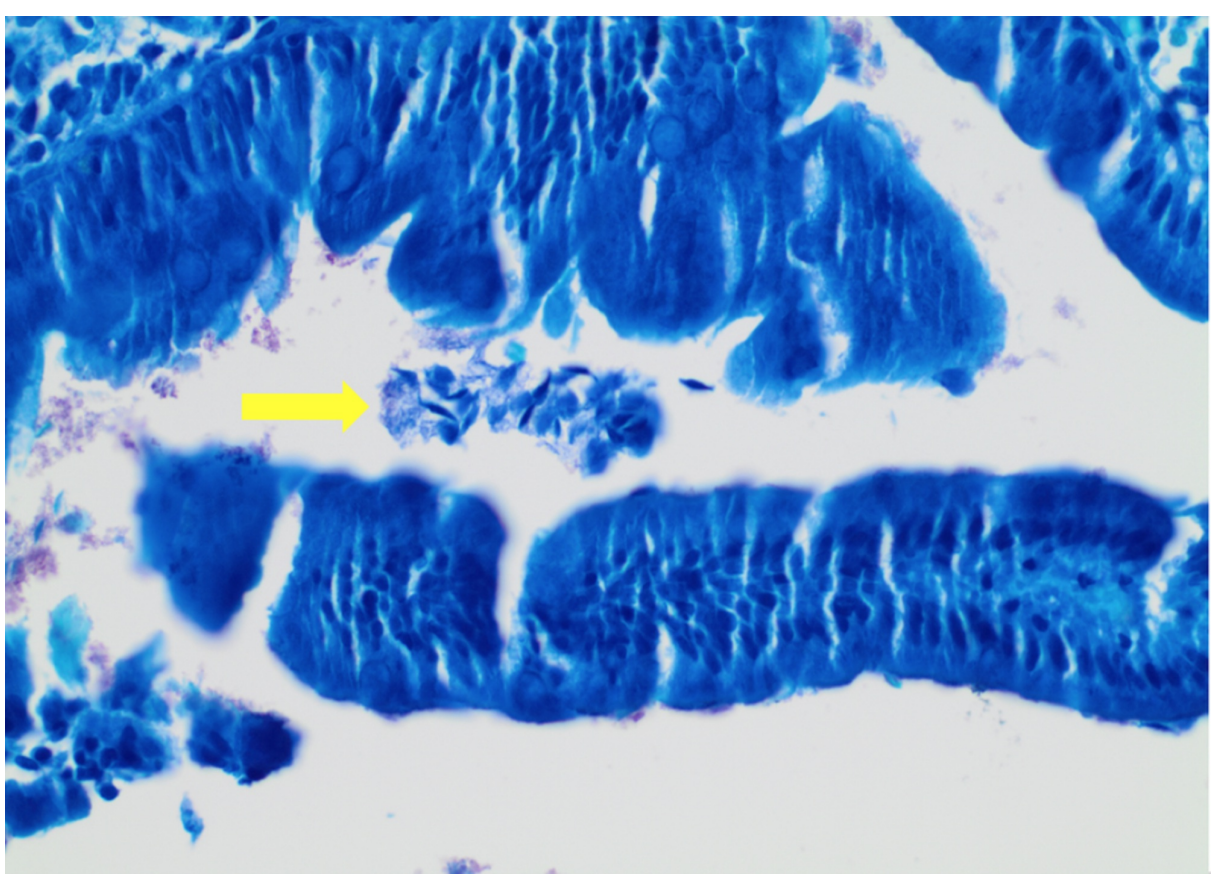

FIGURE 2: Giemsa stain at 40x showing tear-drop-like Giardia 


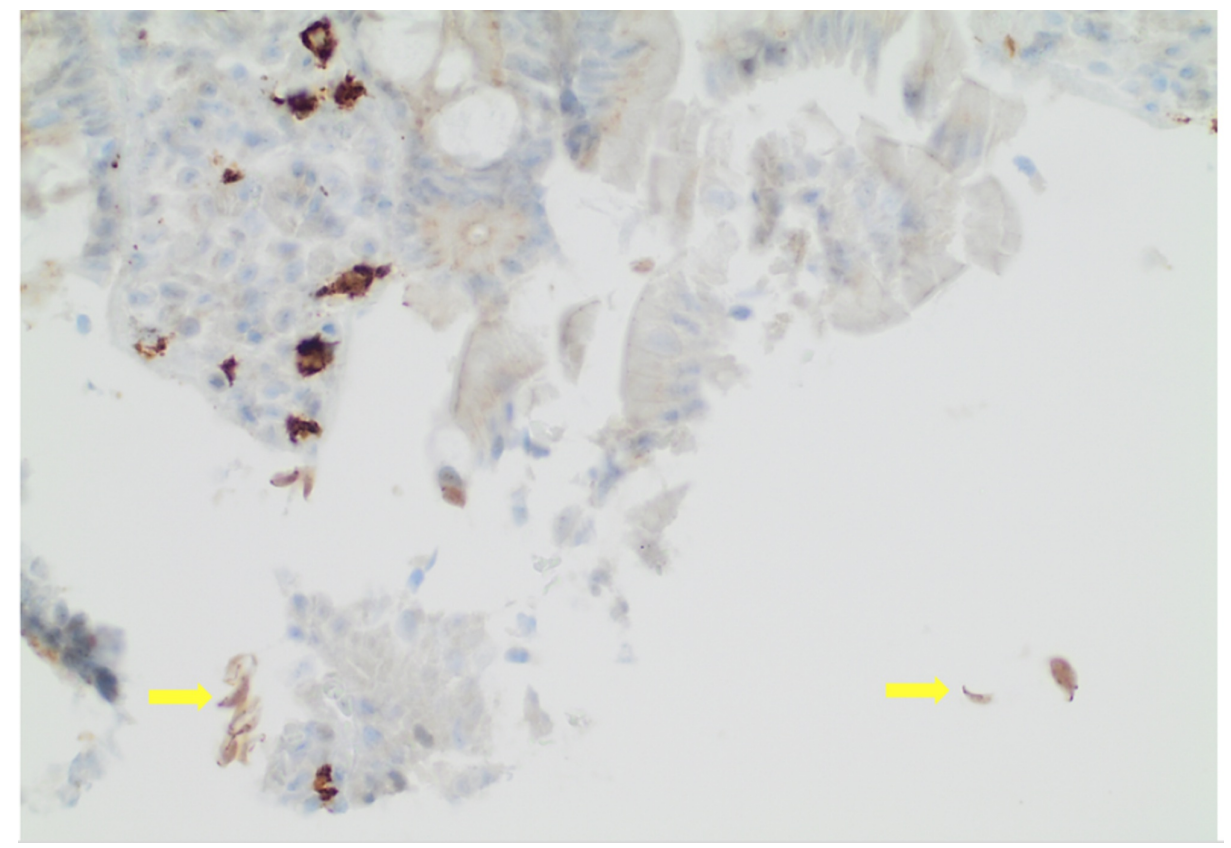

FIGURE 3: CD 117 at 40x. Arrows showing fall-leaves-like Giardia

\section{Discussion}

Giardiasis, an enteric infection caused by the protozoan parasite Giardia, was first described by Leeuwenhoek in 1681, who observed the parasite in his own stool [6]. Giardia duodenalis is the third leading cause of diarrheal illness worldwide mostly affecting the pediatric population. It is an important cause of daycare center outbreaks. In developing countries, prevalence has been reported as high as 20-40 percent. High-risk groups include infants, young children, immunocompromised patients, international travelers, and patients with cystic fibrosis. On the contrary, Giardia infection is not frequently encountered in developed countries. Compared to adults, it is more frequently reported in children aged one to nine years [7]. The reported prevalence of giardiasis in adults was reported as $0.11 \%$ in a cross-sectional study [8]. Male sex, southern region, and the presence of $\mathrm{H}$. pylori have been independently associated with giardiasis [8]. Giardia has two morphological forms. Cysts are the infectious form excreted in the stool. Following cyst ingestion, the trophozoite form is released into the small intestine with some traveling to the large intestine where these are converted to infectious cyst form. Three routes of transmission have been described: waterborne, food-borne, and fecal-oral routes. The most commonly reported symptoms include diarrhea, abdominal pain, nausea, vomiting, anorexia, and weight loss [9]. Asymptomatic infection also occurs, whereas chronic carriers can present with delayed growth and development, weight loss, and fatigue owing to the malabsorption of vitamins and other dietary nutrients. The diagnostic tests include antigen detection assays, nucleic acid detection assays, and stool examination [10]. Out of these tests, stool microscopy is the least sensitive. Treatment is mainly aimed toward supportive care and antimicrobial therapy. Nitroimidazole drugs, i.e., metronidazole and tinidazole, are a highly effective class of drugs. A five- to seven-day course of metronidazole or a single dose of tinidazole can cure more than $90 \%$ of patients [11].

\section{Conclusions}

The clinical presentation of giardiasis varies but it should be kept in the differential diagnoses in appropriate clinical settings such as in adult patients with unexplained iron deficiency anemia. This case emphasizes the fact that giardiasis can occur in the adult population without typical exposure (travel history) and presentation. Although not routinely recommended, EGD with duodenal biopsy can be considered in cases with a high degree of suspicion for giardiasis. Treatment is usually very effective, as mentioned earlier. Therefore, prompt diagnosis is critical.

\section{Additional Information \\ Disclosures}

Human subjects: Consent was obtained by all participants in this study. Conflicts of interest: In compliance with the ICMJE uniform disclosure form, all authors declare the following: Payment/services info: All authors have declared that no financial support was received from any organization for the submitted work. Financial relationships: All authors have declared that they have no financial relationships at present or within the previous three years with any organizations that might have an interest in the submitted work. Other relationships: All authors have declared that there are no other 


\section{Cureus}

relationships or activities that could appear to have influenced the submitted work.

\section{References}

1. Takaoka K, Gourtsoyannis Y, Hart JD: Incidence rate and risk factors for giardiasis and strongyloidiasis in returning UK travellers. J Travel Med. 2016, 23 :taw050. 10.1093/jtm/taw050

2. Adam EA, Yoder JS, Gould LH, Hlavsa MC, Gargano JW: Giardiasis outbreaks in the United States, 19712011. Epidemiol Infect. 2016, 144:2790-2801. 10.1017/S0950268815003040

3. Boreham PF, Upcroft JA, Upcroft P: Changing approaches to the study of Giardia epidemiology: 1681-2000 . Int J Parasitol. 1990, 20:479-487. 10.1016/0020-7519(90)90195-S

4. Mohammed Mahdy AK, Lim YA, Surin J, Wan KL, Al-Mekhlafi MS: Risk factors for endemic giardiasis: highlighting the possible association of contaminated water and food. Trans R Soc Trop Med Hyg. 2008, 102:465-470. 10.1016/j.trstmh.2008.02.004

5. Kappus KD, Lundgren RG Jr, Juranek DD, Roberts JM, Spencer HC: Intestinal parasitism in the United States: update on a continuing problem. Am J Trop Med Hyg. 1994, 5:705-713. 10.4269/ajtmh.1994.50.705

6. Faubert G: Immune response to Giardia duodenalis . Clin Microbiol Rev. 2000, 13:35-54. 10.1128/CMR.13.1.35-54.2000

7. Yoder JS, Gargano JW, Wallace RM, Beach MJ, Centers for Disease Control and Prevention (CDC): Giardiasis surveillance--United States, 2009-2010. MMWR Surveill Summ. 2012, 61:13-23.

8. Zylberberg HM, Green PH, Turner KO, Genta RM, Lebwohl B: Prevalence and predictors of Giardia in the United States. Dig Dis Sci. 2017, 62:432-440. 10.1007/s10620-016-4447-0

9. Muhsen K, Levine MM: A systematic review and meta-analysis of the association between Giardia lamblia and endemic pediatric diarrhea in developing countries. Clin Infect Dis. 2012, 55:S271-S293. $10.1093 / \mathrm{cid} / \mathrm{cis} 762$

10. Heyworth MF: Diagnostic testing for Giardia infections. Trans R Soc Trop Med Hyg. 2014, 108:123-125. 10.1093/trstmh/tru005

11. Gardner TB, Hill DR: Treatment of Giardiasis. Clin Microbiol Rev. 2001, 14:114-128. 10.1128\%2FCMR.14.1.114-128.2001 